\title{
PLANTÃO PSICOLÓGICO EM UNIDADE BÁSICA DE SAÚDE: ATENDIMENTO EM ABORDAGEM HUMANISTA-FENOMENOLÓGICA
}

\author{
Prompt Psychological Attention in Basic Health Unit: \\ Care in Humanistic-phenomenological Approach
}

\author{
Servicio de Emergencia Psicológica en la Unidad Básica de Salud: \\ Atención en el Enfoque Humanista-fenomenológico
}

Lorrany de Oliveira GonÇalves
Marciana Gonçalves Farinha
TOMmy Akira Goto

\begin{abstract}
Resumo: Analisando o psicólogo na Atenção Primária entendemos que, este profissional tem muito a contribuir, seja integrando a equipe ou atuando em parceria com ela. E que este trabalho seria mais abrangente no formato de Plantão Psicológico (PP), que acolhe a pessoa no exato momento de sua necessidade. Este estudo é do tipo qualitativo-fenomenológico e buscou descrever atendimentos psicológicos realizados em uma Unidade Básica de Saúde (UBS). Participaram da pesquisa 13 pessoas, com idades entre 10 e 80 anos, 12 pessoas eram do sexo feminino e 1 do sexo masculino, a maioria eram de baixa escolaridade e de baixa renda. Foram atendidos, primeiramente no formato de PP e, quando necessário, os clientes foram convidados a seguirem em psicoterapia. Os atendimentos foram orientados teoricamente pela abordagem Fenomenológico-Existencial. A maioria dos participantes apresentou queixa de depressão, mostrando vincular-se a problemas familiares. Houve outras queixas como luto, ansiedade, gravidez, e um caso da patologia de transtorno obsessivo compulsivo. Uma grande parcela dos clientes preferiu buscar outro plantão se sentissem necessidade a seguir um processo psicoterapêutico. Conclui-se que o Plantão Psicológico é um instrumento viável e pertinente na prevenção e promoção de saúde.
\end{abstract}

Palavras-chave: Fenomenologia; Plantão psicológico; Atenção primária.

Abstract: Analyzing the psychologist's role in primary health care we understand this occupation can contribute complementing or being partner of the medical staff. We understand this work could be wider in a prompt psychological attention (PP), in which we can attend the patients in the moment of their needs. This study is qualitative-descriptive and tries to analyze psychological assistances made in a medical center (MC). This research comprehends 13 people between 10 and 80 years old; 12 people are female and 01 male. Most of them have low income and low education level. Firstly, these assistances happened as PP and, when necessary, the patients were invited to continue their assistance in psychotherapy. These assistances had as theoretical background existential-phenomenological. Most patients presented complaints of depression linked to their families. There were others complaints linked to mourning, anxiety, pregnancy, and one case of obsessive-compulsive disorder. Many patients preferred to seek PP again whenever they felt the need instead of starting a psychotherapy. We conclude that prompt psychological attention (PP) is a viable and pertinent instrument for health care and prevention.

Keywords: Phenomenology; Prompt psychological attention; Primary health care.

Resumen: Al analizar el psicólogo en la Atención Primaria hemos entendido que esto profesional tiene mucho que cooperar, sea añadido al equipo, sea actuando junto a ella. Además, que esto trabajo sería más abarcador en el formato de Plantón Psicológico (PP), el cual acoge a la persona en el exacto momento de su necesidad. Esta investigación es cualitativo descriptivo y buscó hacer un análisis de las atenciones psicológicas realizadas en un puesto médico. Cooperaron en la investigación 13 personas, con edades entre 10 a 80 años, 12 personas eran del sexo femenino y 1 del masculino, en que la mayoría era de baja escolaridad y de baja renta. Han sido atendidos, en primer momento, en el formato de PP y, cuando fuera necesario, los clientes fueron invitados a seguir en la psicoterapia. Las atenciones han sido orientadas teóricamente por el abordaje fenomenológico existencial. La mayoría de los participantes presentaron la queja de depresión atadas a problemas familiares. Además, otras quejas como luto, ansiedad, embarazo y un caso de la patología de trastorno obsesivo compulsivo. Una gran parcela de los clientes ha preferido buscar otro plantón si tuviera necesidad para seguir un proceso psicoterapéutico. Así, se concluye que el Plantón Psicológico es un instrumento viable e pertinente a prevención y promoción de salud.

Palabras-clave: Fenomenología; Atención psicológica; Atención primaria. 


\section{Introdução}

Este relato de experiência se deu a partir da parceria universidade e Unidade Básica de Saúde (UBS) que incluía no serviço de saúde Programa de Estratégia de Saúde da Família (ESF) duas equipes de Saúde da Família. A universidade, a partir dessa parceria, oferecia atendimento psicológico à população atendida pelo serviço de saúde através de estagiários do curso de Psicologia. Os usuários seriam encaminhados pelos profissionais que ali atendiam, médicos e enfermeiros que faziam seus acompanhamentos de rotina.

Após a Constituição de 1988, o Brasil assume o compromisso de reorganizar seu modelo de atenção à saúde a partir da perspectiva de saúde como direito de cidadania e como recurso que apoia o desenvolvimento individual e coletivo, agregando práticas assistenciais, preventivas e educativas. Os níveis de atenção à saúde passam então a ser representados pela promoção, proteção e recuperação da saúde, priorizando o caráter preventivo e não mais só curativo. Trata-se de um modelo centrado na qualidade de vida e na relação das equipes de saúde com a comunidade. $\mathrm{O}$ que tem dado origem as várias estratégias e programas de intervenção, entre eles a ESF, baseadas no princípio de saúde como direito de todos e objetivando garantir a promoção da saúde através de um atendimento acessível a todos, de forma contínua, integral e de qualidade. (Souza e Carvalho, 2013), mas que não dá conta de todas as demandas que a comunidade apresenta.

E quanto às políticas de saúde, duas importantes iniciativas que se articulam nesse processo de ações na relação estabelecida entre saúde mental e atenção básica vêm sendo implantadas: a Política Nacional de Humanização (PNH) e o apoio matricial, utilizados pelo Ministério da Saúde como arranjo organizacional que visa estabelecer ações conjuntas. Desde 2008, as equipes matriciais têm sido formadas através dos Núcleos de Apoio à Saúde da Família (NASF), e têm como recomendação a existência de, pelo menos, um profissional de saúde mental como parte da equipe multiprofissional, e, em 2009, a PNH foi pensada para a Atenção Básica à Saúde (ABS) tomando como parâmetro a Política Nacional de Atenção Básica (PNAB). O importante é promover saúde tendo em mente que o ser que busca atendimento na unidade é um ser biopsicossocial e precisa ser compreendido em sua multidimensionalidade e complexidade, o que exige um trabalho multidisciplinar (Archanjo \& Schraiber, 2012).

Ao analisar o trabalho do psicólogo nesta equipe entendemos que, apesar das dificuldades, existe um lugar para o psicólogo no PSF, seja integrando o grupo de profissionais ou atuando em estreita parceria com ele. Os princípios que se baseiam o PSF coadunam com aqueles que fundamentam o trabalho do psicólogo independentemente da corrente teórica que o oriente, isto é, o incentivo a autonomia, a valorização das singularidades e dos diferentes saberes, o resgate da cidadania e o desen- volvimento das potencialidades dos indivíduos (Ferreira Neto, 2004). A aproximação com a comunidade, além de permitir o acolhimento de todos que sofrem de maneira equitativa, traz uma compreensão maior do universo com o qual se está trabalhando. O significado deve ser buscado na realidade que dá sentido à vida da pessoa, e não nos conceitos teóricos ou na contextualização dos valores do profissional que se dispõe a ajudar (Soares, 2005).

Dimenstein (1998) aponta que a Psicologia pode ser mais útil ao campo da assistência pública à saúde a partir do momento que sua cultura profissional passe a fornecer modelos ampliados de atuação. Esse é um dos grandes desafios que o psicólogo enfrenta no campo da assistência pública à saúde, na medida em que implica na substituição do paradigma da clínica pelo da saúde pública, o que requer um novo modelo de atenção à saúde e de relação com o usuário, além de um modo sempre dinâmico de fazer saúde.

Devido ao grande número de atendimentos nestas instituições percebemos que o trabalho do psicólogo se tornaria mais abrangente se, no conjunto de suas responsabilidades de trabalho, fossem incluídos o formato de Plantão Psicológico (PP). Como apontado por Rebouças e Dutra (2010) o psicólogo clínico contemporâneo deve se comprometer com a escuta e o acolhimento dos clientes onde quer este esteja. Um aspecto a ser destacado é que esta modalidade de atendimento pode ser uma solução para instituições com grande demanda de atendimento psicoterápico e, muitas vezes, estas pessoas podem se beneficiar de conversar com o psicólogo em um ou mais encontros não necessitando de psicoterapia (Palmieri \& Cury, 2007). A sua base teórica foi fundamentalmente humanista e nos contextos onde esta modalidade de atendimento foi difundida, teve como referência a proposta do Serviço de Aconselhamento Psicológico da Universidade de São Paulo (USP).

Essa modalidade de atendimento surgiu no Brasil em um contexto de grande procura pelo atendimento psicoterápico e a dificuldade em seguir processos de terapia longos por grande parcela da população que buscava ajuda em questões urgentes e pontuais. Nesse sentindo Souza e Souza (2011) defendem que essa modalidade de atendimento favorece dar conta da diversidade e singularidade das demandas psicológicas que se apresentam na realidade de um PP ressaltam ainda a importância de políticas públicas que apoiam a oferta de serviços e dispositivos que assistem a população que procura o serviço. Morato (1997) acredita que o plantonista tem um papel de transformador e multiplicador social.

Nas palavras de Morato (1999) o plantão surgiu ouvindo as demandas sociais e propondo novos modelos que dessem conta desse pungente pedido. “...amalgamando essas experiências passou a repensar como a origem das tensões, conflitos e crises dos homens e pessoas encontram-se nas diversas situações do relacionamento humano, Ou seja, da condição humana no mundo com os outros" (p. 82). 
O PP pode ser servir tanto para oferecer uma escuta que alivia uma angústia como funcionar como um serviço de emergência. Gomes (2012) observa que uma emergência pode ser desde um risco de autoextermínio como um rompimento afetivo com uma pessoa com fortes laços afetivos. Cautela (2004) chama a atenção para essa modalidade de atendimento pode contribuir com o aperfeiçoamento da saúde pública no quesito ajuda psicológica.

Esse formato de atendimento podemos entender como clínico e investigativo, à medida que busca clarificar a queixa junto àquele que traz a demanda a partir dele mesmo, favorecendo não só o acolher em seu sofrimento psicológico/existencial, mas também o ajudando a lidar com a situação-problema e criando possibilidades de clarificação e enfrentamento (Morato, 2006). Chaves e Henriques (2008) defendem o PP como um tipo de intervenção psicológica que acolhe a pessoa no exato momento de sua necessidade, ajudando-a a lidar com a dificuldade tomando conhecimento de seus limites e descobrindo recursos próprios antes desconhecidos. Essa ação psicológica, nas palavras de Braga, Mosqueira e Morato (2012), é entendida como:

(...) atenção psicológica, via plantão psicológico, o ouvir se apresenta como abertura à compreensão de mal-estares em relações situadas, possibilitando ressignificações da experiência. Acompanhar o outro na expressão do que lhe dói, apreendendo-o em sua realidade, é solicitude, disponibilizar-se via escuta que pode permitir se manifestarem elementos norteadores do agir cotidiano, clareando os modos de singularização e permitindo a apropriação de sentido no existir. (p. 557)

O psicólogo, no lugar de escuta, na compreensão do relato daquele que, muitas vezes, tomado de sofrimento psicológico/existencial vai ao seu encontro, pode apreender os pontos de desordem ou de estagnação, facilitando o discurso do cliente e permitindo que os aspectos conflitivos emerjam. O surgimento dos aspectos conflitivos na fala do cliente, ao se deixar afetar pela fala do terapeuta, pode proporcionar o desvelamento, mantendo a questão pela angústia. Desta forma, pela reflexão de si mesmo, o cliente pode descobrir-se em liberdade na escolha de suas possibilidades.

Ressalta-se que o cuidado que o plantonista oferece: a escuta, as reflexões que propõe considerando quem é que busca a ajuda, assim como a situação existencial e socioambiental da pessoa que busca atendimento no plantão possibilitam que o cliente seja acolhido em sua dor no momento exato ou bem próximo da situação que emergiu a sua necessidade, sem precisar de agendamentos ou aguardar em fila de espera. Tassinari (2009, p. 156) afirma que o Plantão Psicológico é “[...] realizado em uma ou mais consultas sem duração predeterminada. Scorsolini-Comin (2014) ressalta que o atendimento pode ser um só ou se desdobrar em outros quando necessário. Farinha e
Souza (2016, p. 75) relembram que “...o tempo da consulta e os possíveis retornos dependem de decisões conjuntas entre o psicólogo e o sujeito atendido, não requerendo a necessidade de horário agendado”.

É um espaço privilegiado de escuta e acolhimento, favorecendo a instrumentalização das pessoas para lidar com suas dificuldades como é o caso de situações de violência e resguardando os direitos das pessoas que procuram a instituição (Farinha \& Souza, 2016). Para essas autoras, o plantão pode ser espaço facilitador para processos de (res)significações de experiências emocionais.

Se pensarmos a partir da perspectiva de atendimento à demanda das instituições de saúde, impõe-se a necessidade de abandonar concepções tradicionais da clínica, abrindo propostas como a do Plantão Psicológico para contemplar as emergências trazidas aos serviços de saúde. Não devemos esquecer que a atuação do psicólogo se encontra sempre em processo e requer outros conhecimentos que deem conta da complexidade do ser humano. Isso pode ser observado não só pela recente participação e atuação do profissional psicólogo nas políticas públicas, nas ações e intervenções com pessoas que tem seus direitos violados e, ainda, em diferentes campos de atuação novos e desafiadores, mas, também, pela concepção tradicional de sua formação clínica desde o início da profissão. Nessa direção, Scorsolini-Comin (2014) aponta que deve-se considerar que o saber psicológico não é a única verdade e deve servir a população através do contato com outras práticas igualmente potencializadoras de bem-estar e de crescimento pessoal.

Em síntese, pode-se dizer que o trabalho realizado pelos programas de atenção básica na Unidade Básica de Saúde é a prestação de atendimentos na unidade ou no domicílio, por uma equipe multiprofissional composta por médico, enfermeiro, auxiliar de enfermagem e agentes comunitários de saúde. A equipe é levada a conhecer a realidade das famílias do território atendido e pelas quais é responsável, por meio de cadastramento e diagnóstico de suas características, tornando-se mais sensível às necessidades dos indivíduos atendidos. Estes conceitos da Saúde e de atuação do psicólogo na atualidade nos ajudam a pensar e norteiam o trabalho dos psicólogos em uma Unidade Básica de Saúde.

A proposta deste trabalho consistiu no relato de experiência de uma estagiária que atendeu em PP em uma Unidade Básica de Saúde (UBS), através do estágio em Psicologia Clínica, objetivando apontar quais são as demandas encontradas e as possíveis intervenções do psicólogo na instituição.

\section{Aspectos metodológicos}

Este trabalho é um relato de experiência, a partir de atendimentos em PP psicológico oferecido em uma UBS. As situações clínicas aqui apresentadas buscam descrever 
e compreender de modo particular o fenômeno investigado, o plantão psicológico. $\mathrm{O}$ intuito desse estudo é subsidiar reflexões mais abrangentes no campo do atendimento clínico em diferentes contextos com grande demanda e poucos recursos financeiros e de profissionais.

\section{O espaço da prática}

A UBS, localizada em uma cidade do interior de Goiás, oferece os seguintes profissionais: técnicos de enfermagem, enfermeiros, nutricionistas, odontólogos, médicos (clínico geral, pediatra, nefrologista, endocrinologista e cardiologista), assistente social e psicólogo, que trabalhavam das 7 às 17 horas em horários predefinidos. O espaço oferecido para os atendimentos da Psicologia consiste em consultórios da unidade, que estivessem disponíveis no momento. Os pacientes foram atendidos pela estagiária de Psicologia, no formato de PP realizados em diferentes horários pré-definidos pela disponibilidade de salas e da aluna de psicologia. Os atendimentos não tinham duração delimitada a priori e eram definidas entre usuário que estava sendo atendido e a plantonista bem como a necessidade de retorno ao plantão. Cada atendimento era discutido nas supervisões semanais, realizados por uma psicóloga. Quando havia necessidade de atendimento psicoterápico, os usuários eram encaminhados para uma clínica-escola da cidade que oferecia a modalidade de serviço. A duração do estágio foi de março a dezembro de 2013 e foi norteado teoricamente pela abordagem fenomenológica-existencial.

Os usuários foram encaminhados pelos profissionais da UBS quando identificavam uma demanda psicológica. Após a escuta e atendimento do usuário, quando necessário, era oferecido encaminhamento para outros serviços, que serão explicitados na próxima sessão deste artigo.

\section{Caracterizando as pessoas atendidas}

No período do estágio, foram atendidas 13 pessoas, com idades entre 10 e 80 anos. Com relação ao sexo, 12 foram do sexo feminino e 1 do sexo masculino, a maioria, 7 pessoas tinham Ensino Fundamental, 5 fizeram 0 ensino médio e 1 ainda cursava o ensino médio. Quanto à renda familiar, 6 pessoas possuíam renda entre 1 e três salários mínimos e 5 tinham renda entre 4 e 6 salários mínimos. Sobre a queixa principal, 6 pessoas relataram ter depressão, 13 pessoas relataram problemas familiares, 3 disseram estar passando pelo luto, 1 apresentou transtorno obsessivo compulsivo, 2 foram diagnosticadas com depressão pós-parto. Em números de encontros 6 pessoas compareceram a mais de uma sessão. Como apresentado no quadro abaixo:

\section{Dados dos participantes}

\begin{tabular}{|c|c|c|c|c|c|c|}
\hline $\mathrm{N}^{\mathbf{0}}$ & Sexo & Idade & Escolaridade & Renda Familiar & Queixa Principal & $\begin{array}{l}\mathrm{N}^{0} \text { de encontro } \\
\text { realizado }\end{array}$ \\
\hline 1 & $\mathrm{~F}$ & 68 & $\begin{array}{c}\text { Ensino Fundamental } \\
\text { incompleto }\end{array}$ & $\begin{array}{c}\text { Entre } 1 \text { e } 3 \text { salários } \\
\text { mínimos }\end{array}$ & Depressão, esquecimento, problemas familiares. & 4 \\
\hline 2 & $\mathrm{~F}$ & 73 & Semi-analfabeta & $\begin{array}{c}\text { Entre } 1 \text { e } 3 \text { salários } \\
\text { mínimos }\end{array}$ & Depressão Grave, choro, problemas familiares & 35 \\
\hline 3 & $\mathrm{~F}$ & 35 & $\begin{array}{l}\text { Ensino fundamental } \\
\text { completo. }\end{array}$ & $\begin{array}{c}\text { Entre } 4 \text { e } 6 \text { salários } \\
\text { mínimos }\end{array}$ & Gravidez, ansiedade, problemas conjugais & 1 \\
\hline 4 & $\mathrm{~F}$ & 65 & $\begin{array}{c}\text { Ensino médio } \\
\text { completo }\end{array}$ & $\begin{array}{c}\text { Entre } 1 \text { e } 3 \text { salários } \\
\text { mínimos }\end{array}$ & Depressão, Luto, solidão. & 1 \\
\hline 5 & $\mathrm{~F}$ & 58 & $\begin{array}{l}\text { Ensino fundamental } \\
\text { completo }\end{array}$ & $\begin{array}{c}\text { Entre } 1 \text { e } 3 \text { salários } \\
\text { mínimos }\end{array}$ & Depressão, luto, fraqueza, problemas familiares & 1 \\
\hline 6 & $\mathrm{M}$ & 54 & $\begin{array}{l}\text { Ensino médio } \\
\text { incompleto }\end{array}$ & $\begin{array}{c}\text { Entre } 4 \text { e } 6 \text { salários } \\
\text { mínimos }\end{array}$ & Problemas por ser ex-presidiário, problemas familiares & 4 \\
\hline 7 & $\mathrm{~F}$ & 17 & $\begin{array}{l}\text { Ensino fundamental } \\
\text { incompleto }\end{array}$ & $\begin{array}{c}\text { Entre } 1 \text { e } 3 \text { salários } \\
\text { mínimos } \\
\end{array}$ & Gravidez, problemas conjugais. & 1 \\
\hline 8 & $\mathrm{~F}$ & 37 & $\begin{array}{l}\text { Ensino médio } \\
\text { incompleto }\end{array}$ & $\begin{array}{c}\text { Entre } 4 \text { e } 6 \text { salários } \\
\text { mínimos }\end{array}$ & Problemas familiares, briga com o irmão. & 1 \\
\hline 9 & $\mathrm{~F}$ & 79 & $\begin{array}{l}\text { Ensino Médio } \\
\text { completo }\end{array}$ & $\begin{array}{c}\text { Entre } 4 \text { e } 6 \text { salários } \\
\text { mínimos }\end{array}$ & $\begin{array}{l}\text { Transtorno Obsessivo compulsivo, lava as mãos e a } \\
\text { boca com muita frequência, senti bichinhos no corpo } \\
\text { esquecimento, problemas com os filhos. }\end{array}$ & 11 \\
\hline 10 & $\mathrm{~F}$ & 23 & $\begin{array}{l}\text { Ensino médio } \\
\text { incompleto }\end{array}$ & $\begin{array}{c}\text { Entre } 1 \text { e } 3 \text { salários } \\
\text { Mínimos } \\
\end{array}$ & $\begin{array}{c}\text { Depressão pós-parto, } \\
\text { Imagina-se matando os filhos. }\end{array}$ & 1 \\
\hline 11 & $\mathrm{~F}$ & 22 & $\begin{array}{l}\text { Ensino médio } \\
\text { incompleto }\end{array}$ & $\begin{array}{c}\text { Entre } 4 \text { e } 6 \text { salários } \\
\text { mínimos }\end{array}$ & $\begin{array}{l}\text { Insônia, Problemas conjugais, o marido mora em outro } \\
\text { país, problemas familiares. }\end{array}$ & 5 \\
\hline 12 & $\mathrm{~F}$ & 10 & $\begin{array}{l}\text { Ensino fundametal } \\
\text { incompleto }\end{array}$ & $\begin{array}{l}\text { Entre } 4 \text { e } 6 \text { salários } \\
\text { mínimos }\end{array}$ & Separação dos pais, choro. & 6 \\
\hline 13 & $\mathrm{~F}$ & 15 & $\begin{array}{l}\text { Ensino fundamental } \\
\text { completo }\end{array}$ & $\begin{array}{l}\text { Entre } 4 \text { e } 6 \text { salários } \\
\text { mínimos }\end{array}$ & $\begin{array}{l}\text { Mudanças de Humor muito acentuada, indecisão para o } \\
\text { vestibular, problemas familiares, timidez. }\end{array}$ & 1 \\
\hline
\end{tabular}


Os dados dos atendimentos, problemáticas apresentadas, dificuldades dos plantonistas foram relatados em seus diários de bordos que serão trazidos aqui para subsidiar as discussões. Os nomes de todas as pessoas foram trocados para resguardar os princípios éticos. Os relatos apresentados são ilustrativos dos atendimentos realizados pelas plantonistas.

\section{Resultados e discussão}

É importante destacar que os psicólogos que se vinculam à fenomenologia-existencial não restringem sua visão de ser humano, ou mesmo de personalidade ou pessoa, em grupos ou diagnósticos categóricos. Ao contrário, compreendem o existir humano em sua totalidade existencial em um constante devir de seu ser. Ainda, esse existir humano é caracterizado por ser-relacional, ou seja, existe mantendo uma intrínseca relação com o mundo (ser-no-mundo), com os outros existentes (ser-com-os-outros) e com si mesmo (ser-próprio). Como destaca Goto (2003):

A Psicologia Humanista-Existencial possui diferentes enfoques descritivos do psicológico, não por serem contraditórios, mas por essa abordagem permitir uma abertura na interpretação da vivência psicológica. O fundamento básico desta abordagem é sustentado pela descrição do vivido no contexto do ser, isto é, a descrição da vivência dentro de seus diversos modos-de-ser. Desta forma, a psicologia humanista vê-se fortemente entrelaçada com a ontologia, pois seria impossível falar do homem sem localizar sua existência no mundo. (p. 157)

Assim, as reflexões aqui propostas foram analisadas a partir dessa psicologia humanista-existencial, fundamentando o fazer do PP. Nisso, como destacam Rebouças e Dutra (2010), compreendemos esses indivíduos a partir de suas experiências e dos significados que eles atribuem ao mundo, levando em consideração o contexto no qual estão inseridos, considerando-os como um ser-no-mundo e, portanto, constituídos por este, ao mesmo tempo em que o constituem.

Das queixas apresentadas foram, principalmente, questões referentes à desestruturação familiar. Nesta temática estavam: separação dos pais, problemas conjugais, relação pais e filhos, e irmãos. E os atendimentos se nortearam então, pela queixa principal de depressão, relatada por 6 participantes, que disseram possuir o diagnóstico e estarem medicadas e apresentando choro e tristeza, apesar do uso da medicação prescrita. Mas, como aponta Braga, Mosqueira e Morato (2012), clinicamente, não se escutam queixas puramente, pois se relacionam à interpretação de sua realidade, onde se dá as relações da vida em situações com outros nos cenários do cotidiano. O Plantão Psicológico, como metodologia interventiva da ação psicológica, ocorre como um acontecimento; trata-se de uma paragem na qual o psicólogo, testemunha o entre, a condição do cliente de ser em história. Pelo jogo interpretativo, é possível deixar ver um sentido na temporalização de uma experiência, revelando filamentos desconexos.

Outra característica dos atendimentos que pudemos observar foi o predomínio do sexo feminino buscando pelo atendimento, o que corrobora com outros estudos (Fonseca, Fialho, Matos \& Figueira, 2013; Estupiña et al, 2012; Pirkis et al, 2011) indicando talvez, entre outras coisas, maior resistência masculina à intervenção ou busca por ajuda psicológica ou ainda maior frequência de problemas emocionais, como a depressão, em mulheres, o que foi uma das nossas maiores queixas e reflete dados de outros estudos (Borooah, 2010).

Segundo Dalgalarrondo (2008), do ponto de vista psicopatológico, as síndromes depressivas têm como elementos mais salientes o humor triste e o desânimo. Entretanto, elas caracterizam-se por uma multiplicidade de sintomas afetivos, instintivos e neurovegetativos, ideativos e cognitivos, relativos à auto valoração, à vontade e à psicomotricidade. Também podem estar presentes, em formas graves de depressão, sintomas psicóticos (delírios e/ou alucinações), marcante alteração psicomotora (geralmente lentificação ou estupor) e fenômenos biológicos (neuronais ou neuroendócrinos) associados. Este autor ressalta ainda que as síndromes depressivas são atualmente reconhecidas como um problema prioritário de saúde pública.

Houve outras queixas como luto, ansiedade, gravidez, depressão pós-parto, e um caso da patologia de transtorno obsessivo compulsivo. Sendo a maioria dessas queixas relacionadas aos sentimentos depressivos ou ansiosos. Como aponta Dalgalarrondo (2008), essas sensações e sentimentos podem estar em alguns casos associados, podendo se apresentar concomitantemente ou isoladamente. Percebemos então, que as queixas dos pacientes se unem às dificuldades que enfrentam no dia a dia e as sintomatologias são o caminho que encontram para enfrentá-las. Observamos que apontam como causas de seus problemas a desestrutura familiar, como uso de drogas, envolvimentos com crimes e agressões.

Os atendimentos deste trabalho se nortearam, como proposto por Palmieri \& Cury (2007), com uma proposta de atenção psicológica acompanhando os pressupostos teóricos e práticos embasados nos pilares da Psicologia fenomenológico-existencial, por meio da noção de respeito ao outro, autenticidade, liberdade de pensamento, possibilidade de escolha e possibilidade de encontro, levando-se em consideração a capacidade unicamente humana de intencionalmente pensar o mundo e as relações por meio de uma consciência reflexiva. Nesse sentido Morato (2006) traz uma reflexão:

(...) Existia um parâmetro do que seria um atendimento clínico em Psicologia, supondo a existência de uma técnica que fornecesse definições, explicações e conceitos que amparassem todas suas ações durante os 
atendimentos. Para o encontro ser caracterizado como "atendimento", o plantonista deveria ter insights: caberia a ele a atribuição de significação a falta de sentido expressa pela pessoa que buscava atendimento. Além disso, ao final do atendimento era necessário que a pessoa apresentasse alguma mudança. Tal situação reflete uma cristalização do modelo clínico tradicional e, nesse sentido, o Plantão era difícil como primeiras experiências para estagiários. Não havia como desconstruir o que ainda não se conhecia, mas que já se havia ouvido falar. (p. 6)

A intervenção psicológica feita com os pacientes foi realizada com a postura do terapeuta e da psicoterapia, de explorar o cotidiano do cliente. Essa postura permite que ao cliente que segundo Feijoo (2000), a partir dessa exploração, busca que ele identifique fatos que desencadearam um determinado modo de sentir as coisas ou de agir, como os fatos que o afetam. E, então, o encontro terapêutico pode se tornar reveladora das situações conflitivas, definida pela autora como, o trazer à tona a inautenticidade. O cliente diz uma coisa e sua aparência parece negá-la, ou tem dois pesos e duas medidas para a mesma situação, isto é, pensamentos, sentimentos e ação não caminham juntos. O terapeuta revela a situação conflitiva que se mostra. Para Ferreira:

Esse tipo de aproximação terapêutica oferece uma atitude acolhedora e não julgadora em relação às experiências do cliente, em que o sentido se desvela sem que seja possível a afirmação de uma resposta definitiva. E esse sentido, uma vez desvelado, assume a cada vez novos significados que vão sendo experimentados a cada encontro. (2009, p. 148)

Corroborando com Rebouças e Dutra (2010), que dizem que o plantão, ao oferecer esse espaço, promove o restabelecimento do ethos que foi perdido, devolvendo ao cliente seu lugar no mundo. Não é necessariamente preciso uma psicoterapia para se sentir bem. Muitas pessoas precisam apenas dessa atitude, desse novo olhar, para que elas possam ser quem realmente são, para que possam se ver como seres únicos, para que tenham aquilo que o mundo atual não lhes permite, mesmo que seja por um breve momento. O PP cria condições para que o indivíduo possa por si só encontrar seus caminhos, mas esta trilha muitas vezes é tortuosa e em alguns momentos o homem precisará desse espaço para se fortalecer e posteriormente continuar. Assim, o PP deve estar à disposição sempre que necessário.

Como aponta Moreira (2009) e acreditamos ser fundamental no PP, a escuta trapêutica se produz na interseção da subjetividade do terapeuta e do cliente. O psicoterapeuta e o plantonista passeiam de mãos dadas com o cliente em seu lebenswelt (mundo-da-vida), buscando sempre compreendê-lo, sem nunca separar-se de seu próprio mundo experiencial. Isto ocorre através da empatia. É interessante assinalar que, entre as repetidas definições desse conceito de empatia - como atitude básica para o terapeuta ou plantonista - e é genial em sua simplicidade porque nenhum processo psicoterapêutico que implique em transformações profundas pode ser levado adiante com êxito se não ocorre a empatia.

Os plantões psicológicos corroboraram com o descrito por Chaves e Henriques (2008), onde a prática de PP foi crescendo gradativamente. Acreditando que no início os envolvidos estavam de certa forma desconfortáveis com tal situação, com o "novo" surgindo, afinal não deixava de ser um desafio implantar o plantão psicológico onde há anos oferecia somente o tratamento clínico tradicional (psicoterapias). Mas, aos poucos, tudo foi se entrelaçando e os plantões sendo cada vez mais procurados pela população. Visto que, em certo momento, foi mais divulgado, o que aproximou ainda mais as pessoas do que estava ocorrendo. Nossa experiência revelou que muitos profissionais da UBS não tinham as informações da realização dos plantões psicológicos, mas quando souberam, passaram a encaminhar os pacientes que estavam tratando para este trabalho. Pudemos perceber que uma grande parcela dos atendimentos realizados no PP teve resolutividade, não necessitando de psicoterapia, demonstrando que o atendimento recebido no PP foi suficiente e/ou resolutivo para aquela demanda.

Outro aspecto observado em alguns relatos é que há motivos específicos para a procura da UBS, sendo estes centrados em procedimentos fragmentados e não por uma assistência terapêutica pautada na responsabilização, vinculação e promoção de saúde. Os pacientes dizem que já estão medicados ou que pediram para os médicos e que esperam melhorar suas tristezas com os remédios. Percebemos então que os ideais que regem o serviço dos profissionais nesta instituição condizem com o contexto dos direitos humanos, oferecendo atividades que os estimulem e, que participando delas, eles possam ampliar ou cuidar de sua qualidade de vida.

Percebeu-se dificuldades enfrentadas pelos profissionais da UBS, como, por exemplo, as faltas dos pacientes para as consultas e serviços oferecidos pelos profissionais da instituição. Pelo olhar dos profissionais, os pacientes só buscam o apoio deles no momento de emergências ou desconforto, como dores. Acreditam que eles não possuem a consciência de que se deve seguir o tratamento ou prevenir as doenças. Como apontam Faquinello, Carreira e Marcon (2010), as UBS deveriam ser a primeira referência de apoio formal procurada pela população para o acompanhamento e para a prevenção em saúde e também no que se refere à busca de orientações e informações que podem ser fornecidas pelos profissionais que ali atuam. No entanto, o que se percebe é que a procura por essas unidades ocorre somente quando eles estão com algum sintoma patológico ou problema físico. Observa-se, assim, que os sujeitos relatam motivos específicos para a procura 
da UBS, sendo estes, geralmente, centrados em procedimentos fragmentados e não por uma assistência terapêutica pautada na responsabilização, vinculação e cuidado ao paciente. Nas falas dos pacientes, aparece outro aspecto para não adesão ao tratamento, a dificuldade de locomoção, visto que muitos moram distantes da UBS. E também relataram falta de tempo disponível devido ao trabalho e outras atividades que consideraram mais importantes.

Nesse sentido, a oferta do PP, como alternativa de intervenção, ao contrário da tradicional oferecida por outros estágios, contribui que muitas pessoas aceitassem serem atendidas já que elas já estavam em atendimento com outros profissionais da UBS, facilitando que não houvesse mais deslocamentos até a unidade. Outro aspecto percebido corrobora com Scorsolini-Comin (2014), que diz que:

(...) A implantação do presente serviço não encontrou dificuldades significativas, mas pode-se destacar a necessidade de esclarecer à população atendida em que consiste uma intervenção psicológica e os elementos éticos desse cuidado. Aspectos como o sigilo das informações e a escuta profissional tiveram que ser destacados e priorizados nos atendimentos, haja vista a pouca familiaridade das pessoas atendidas com a atuação do psicólogo. Outras especificidades referem-se ao manejo do tempo de cada atendimento e da organização do plantão de modo conjugado com as consultas mediúnicas, de modo que uma mesma pessoa pudesse, em um dia, ser atendida tanto pelo médium como pelo psicólogo. (p. 898)

Então, o trabalho do psicólogo, como apontado por Soares (2005), para atender às necessidades da prática cotidiana, explicitadas pelo ESF, é importante a abertura a outros saberes, a criatividade, a disposição para aprender com o que está sendo construído e que, às vezes, não foi ainda teorizado. A novidade, as alternativas estão surgindo da experiência caótica, singular e imprevista. Os psicólogos têm então um desafio, que é o de, incorporando-se ao ESF e ao que ele tem de inovador e reorganizador da assistência, poder enriquecê-lo com a visão do conjunto para cuidar das pessoas de forma integral. Segundo Archanjo e Schraiber (2012), é o momento de ir além e revelar o que o limite mostra novas possibilidades, experimentações e novos conflitos e tensões. O importante é estar ciente de que por mais que se tentem definir padrões, estes deverão ser sempre revisados e avaliados e, cada vez mais, serão difíceis de serem enquadrados como privativos de uma ou outra área do saber.

\section{Considerações finais}

Percebemos que o atendimento em Psicologia é algo novo para o público dessa UBS e é um campo de atuação que muito tem a contribuir tanto com a população atendida como com a equipe de profissionais que ali trabalham. Há que se pensar também que focar a promoção da saúde deveria ser a meta de todos os profissionais da saúde além dos cuidados quando já há um problema instalado.

Este é um campo de trabalho da psicologia que deve ser pensado de forma a adaptar-se a este contexto de saúde. Deve-se então fomentar estudos, para que olhares diferentes e variados possam chegar a um consenso e a um melhor aproveitamento para os pacientes deste serviço. Percebendo o público atendido e a demanda dessas instituições, o PP pode ser uma alternativa para acolher promovendo dinamismo e resolutividade ao serviço de saúde, promovendo saúde e prevenção de agravamento de adoecimentos, contribuindo assim como a UBS e a comunidade.

O PP foi uma alternativa que buscou ofertar um espaço de acolhimento, escuta ativa e respeito. Onde mesmo os atendimentos que aconteceram apenas uma vez proporcionaram a escuta e auxiliaram na reconstrução de recursos que possibilitassem o enfrentamento das adversidades. Foram trabalhadas as questões emergentes, sendo demonstrada a preocupação com a história de vida de cada paciente que procurou o serviço, permitindo um olhar voltado para o indivíduo, seus sentimentos e comportamentos relacionados à sua realidade.

Por isso, concluímos que análises desse tipo e o trabalho do psicólogo em instituições de saúde pública têm muito a contribuir com estas instituições e para a população nelas atendidas. Concluímos que a visão do psicólogo humanista tem o poder de enriquecê-los com a visão do conjunto para cuidar das pessoas de forma integral.

\section{Referências}

Archanjo, A. M. \& Schraiber, L. B. (2012). A atuação dos psicólogos em unidades básicas de saúde na cidade de São Paulo. Saúde Social, 21(2), 351-363.

Borooah, V. K. (2010). Gender Differences in the Incidence of Depression and Anxiety: Econometric Evidence from the USA. Journal Of Happiness Studies, 11, 663-682. doi: 10.1007/ s10902-009-9155-4

Braga, T. B. M.; Mosqueira, S. M. \& Morato, H. T. P. (2012). Cartografia clínica em plantão psicológico: investigação interventiva num projeto de atenção psicológica em distrito policial. Temas em Psicologia, 20(2), 555-570.

Cautella Junior, W. (2004). Plantão Psicológico em hospital psiquiátrico: novas Considerações e desenvolvimento. In: Miguel Mahfoud (Org.) Plantão Psicológico: novos horizontes (p.97 - p.114). São Paulo: Editora CI.

Chaves, P. B. \& Henriques, W. M. (2008). Plantão Psicológico: De frente com o inesperado. Psicologia e Argumento, 26(53), 151-157.

Conselho Federal de Psicologia (1994). Psicólogo brasileiro: práticas emergentes e desafios para a formação. São Paulo: Casa do Psicólogo. 
Dalgalarrondo, P. (2008). Psicopatologia e semiologia dos transtornos mentais. Porto Alegre: Artmed.

Dimenstein, M. D. (1998). O psicólogo nas unidades básicas de saúde: desafios para a formação e atuação profissionais de Saúde. Estudos de Psicologia, 3(1), 53-81.

Estupiña, F. J.; Labrador, F. J., \& Garcia-Vera, M. P. (2012). A study of patients who go to a psychology clinic seeking treatment. Spanish Journal of Psychology, 15, 275-285. doi: 10.5209/rev-SJOP.2012.v15.n1.37334

Farinha, M. G. \& Souza, T. M. C. (2016). Plantão psicológico na delegacia da mulher: experiência de atendimento sócio-clínico. Revista da SPAGESP, 17(1), 65-79.

Faquinello, P.; Carreira, L. \& Marcon, S. S. (2010). A unidade básica de saúde e sua função na rede de apoio social ao hipertenso. Texto Contexto Enfermagem, 19(4): 736-44.

Feijoo, A. M. L. C. (2000). A escuta e a fala em psicoterapia: uma proposta fenomenológica e existencial. São Paulo: Vetor.

Ferreira, L. S. M. (2009). Entre a fenomenologia e a hermenêutica: uma Perspectiva em psicoterapia. Revista da Abordagem Gestáltica, 15(2), 143-148.

Ferreira Neto, J. L. (2004). A formação do Psicólogo: clínica, social e mercado. São Paulo: Escuta.

Fonseca, A. B.; Fialho, T.; Matos, M. G. de \& Figueira, M. L. (2013). Caracterização da população que recorre a uma consulta de psicoterapia hospitalar. Psicologia, Saúde \& Doenças, 14(3), 405-419.

Gomes, F. da M. D. (2012). Plantão psicológico: atendimentos em situações de crise. Vínculo, 9(2), 18-26.

Goto, T.A. \& Gianastacio, V. (2003). A transcendência divina no homem - perspectiva da psicologia humanista-existencial. Revista Correlatio, 3, 157-175.

Morato, H. T. P. (1997). Experiências do Serviço de aconselhamento Psicológico do IPUSP: Aprendizagem Significativa em Ação. Boletim de Psicologia (São Paulo), XLVII (106).

Morato, H. T. P. (1999). Aconselhamento psicológico: uma passagem para a transdisciplinariedade. Em H. T. P. Morato (Org.). Aconselhamento psicológico centrado na pessoa: novos desafios (p. 61-89). São Paulo: Casa do Psicólogo.

Morato, H. T. P. (2006). Pedido, queixa e demanda no Plantão Psicológico: querer poder ou precisar? VI Simpósio Nacional de Práticas Psicológicas em Instituição - Psicologia e Políticas Públicas. (p. 1-8), Vitória: UFES.

Moreira, V. (2009). Da empatia à compreensão do lebenswelt (mundo vivido) na psicoterapia humanista-fenomenológica. Rev. Latinoamericana de Psicopatologia Fundamental, 12(1), 59-70.

Palmieri, T. H. \& Cury, V. E. (2007). Plantão psicológico em Hospital Geral: um estudo fenomenológico. Psicologia: Reflexão e Crítica, 20(3), 472-479.

Pereira, F. M.; Pereira Neto, A. (2003). O psicólogo no Brasil: notas sobre seu processo de profissionalização. Psicologia em Estudo, Maringá, 8(2), 19-27.
Pirkis, J., Bassilios, B., Fletcher, J., Sanderson,K., Spittal, M. J., King, K., \& Blashki, G. (2011). Clinical improvement after treatment provided through the Better Outcomes in Mental Health Care (BOiMHC) programme: do some patients show greater improvement than others? The Australian and New Zealand journal of psychiatry, 45, 289-298. doi: 10.3109/00048674.2010.539195.

Rebouças, M. S. S. \& Dutra, E. (2010) Plantão Psicológico: uma Prática Clínica da Contemporaneidade. Revista da Abordagem Gestáltica, 16(1), 19-28.

Romero, E. (1998). As dimensões da vida humana - existência e experiência. São José dos Campos: Novos Horizontes Editora.

Scorsolini-Comin, F. (2014). Plantão Psicológico Centrado na Pessoa: Intervenção Etnopsicológica em Terreiro de Umbanda. Temas em Psicologia, 22(4), 885-899. http://dx.doi. org/10.9788/TP2014.4-16.

Soares, T. C. (2005) "A vida é mais forte do que as teorias" o psicólogo nos serviços de atenção primária à saúde. Psicologia ciência e profissão, 25(4), 590-601.

Souza, R. A. \& Carvalho, A. M. (2013). Programa de Saúde da Família e qualidade de vida: um olhar da Psicologia. Estudos de Psicologia (Minas Gerais), 8(3), 515-523.

Souza, B. N. de, \& Souza, A. M. de. (2011). Plantão psicológico no HUBFS: uma experiência de assistência à comunidade. Revista do NUFEN, 3(1), 200-209.

Tassinari, M. A. (2009). Plantão Psicológico como promoção de saúde. Em Anita Bacelar (Org.). A psicologia humanista na prática: reflexões sobre a Abordagem Centrada na Pessoa (p. 185-201). Palhoça, Ed. UNISUL.

Lorrany de Oliveira Gonçalves - Psicóloga pela Universidade Federal de Goiás - Campus Jataí.

Marciana Gonçalves Farinha - Psicóloga, Doutora em Enfermagem Psiquiátrica pela Universidade de São Paulo, Professora Adjunta do Instituto de Psicologia da Universidade Federal de Uberlândia. Endereço Institucional: Universidade Federal de Uberlândia, Faculdade de Artes, Filosofia e Ciências Sociais, Faculdade de Psicologia. Av. Pará, 1720 (Bairro Umuarama). CEP: 38400902 - Uberlândia/MG. E-mail:mgfarinha@hotmail.com

Tommy Akira Goto - Psicólogo, Doutor em Psicologia pela Pontifícia Universidade Católica de Campinas, Docente Adjunto do Instituto de Psicologia da Universidade Federal de Uberlândia. Membro do GT de Fenomenologia da Associação Nacional de Pós-Graduação em Filosofia (ANPOF); Membro do GT de Psicologia \& Fenomenologia da Associação Nacional de Pesquisa e Pós-Graduação em Psicologia (ANPEPP). É presidente fundador da Associação Brasileira de Psicologia Fenomenológica, Membro-colaborador do Circulo Latinoamericano de Fenomenologia (CLAFEN), Membro Oridinário da "Asociación Internacional de Fenomenología y Ciencia Cognitiva" e Membro-assistente da Sociedad Iberoamericana de Estudios Heideggerianos SIEH e membro da Associacion Latinoamericana de Psicologia Existencial (ALPE). E-mail:prof-tommy@hotmail.com

Recebido em 16.12.2015 Primeira Decisão Editorial em 02.03.2016 Segunda Decisão Editorial em 02.08.2016 Aceito em 24.08.2016 